\title{
An Introduction to NATO Standard ANEP (Allied Naval Engineering Publication) 77 and Its Application to Naval Ships
}

Introducción a la Norma de la OTAN ANEP (Publicación de Ingeniería Naval Aliada) 77 y su aplicación a los buques navales

DOI: $10.25043 / 19098642.153$

Richard D. Delpizzo CAPT, USNR (ret) ${ }^{1}$

Sharat Valluri ${ }^{2}$

\begin{abstract}
In a dynamic world of continuously evolving design and application of innovative new technologies, it is proving increasingly challenging to apply the traditional approach of prescriptive-based standards. As a result, attention has focused on the increased use of a goal based philosophy over the detailed technical standards often incorporated in rules and regulations. A successful application of this approach has been witnessed in providing goal based requirements to the design of safety for naval vessels.
\end{abstract}

Key words: ABS, ANEP, GBS, goal based standard, INSA, NATO, NSCA, naval, safety.

\section{Resumen}

En un mundo dinámico de constante evolución en diseño y aplicación de nuevas tecnologías innovadoras, está resultando cada vez más difícil aplicar el enfoque tradicional de los estándares basados en normas prescriptivas. Como resultado, la atención se ha centrado en el uso creciente de una filosofía basada en objetivos por encima de los estándares técnicos detallados que a menudo se incorporan en reglas y regulaciones. Una aplicación exitosa de este enfoque se ha evidenciado en la proporción de requisitos basados en objetivos al diseño de la seguridad para los buques navales.

Palabras claves: ABS, ANEP, GBS, estándar basado en objetivos, INSA, OTAN, NSCA, naval, seguridad.

Date Received: February $28^{\text {th }} 2017$ - Fecha de recepción: Febrero 28 de 2017

Date Accepted: March 10 2017 - Fecha de aceptación: Marzo 10 de 2017

\footnotetext{
${ }^{1}$ Director, International Government Services, American Bureau of Shipping. USA. (ABS) Email: RDelpizzo@eagle.org

${ }^{2}$ Director, Technology \& Business Development, International Government Services, American Bureau of Shipping (ABS). USA. Email: svalluri@eagle.org
} 


\section{Introduction}

Our current environment of increasing computational speeds, along with the many complex analytical methods available to naval architects and marine engineers, has resulted in many novel approaches to ship design. Some of these design innovations are on a system scale, while others address the overall arrangement of the marine platform. In a dynamic world of evolving design, it is proving increasingly challenging to apply the traditional approach of prescriptive based standards. As a result, attention has focused on the increased use of a goal based philosophy over the detailed technical standards more typically incorporated in rules and regulations.

Typical goal based standards (GBS) contain tiers that provide progressively more detailed information. In essence, GBS are intended for developers of standards, not as the standard itself. Once a comprehensive standard is created, designers apply it to their ship. Using a goal based philosophy for naval ship safety, NATO ANEP 77 (known as the Naval Ship Code) provides the first high-level comprehensive safety standard for combatant and noncombatant military ships. Put simply, ANEP 77 is a sort of naval version of IMO SOLAS (Safety of Life at Sea, a convention of the International Maritime Organization) and is being applied to many NATO and non- NATO warships around the world.

This document presents the genesis of goal based standards in the commercial maritime industry and discusses the existing maritime treaty (IMO SOLAS) that forms the basis for the Naval Ship Code. It describes the historical evolution leading to the current standard - which was created as a product of both navies and classification societies engaged in naval and maritime defense work providing a short overview of the governing bodies for ANEP 77, namely the International Naval Safety Association (INSA) and the Naval Ship Classification Association (NSCA).

Finally, this paper suggests a process for applying the Naval Ship Code to a naval combatant and provides guidance on how that process would be applied.

\section{The trend toward goal based standards}

Most of the standards used in technical fields are prescriptive in nature; for example, they may cite specific materials to be used; numerical tolerances to be adhered to; building plans to be followed; or test criteria that must be satisfied. Of course, many more examples can be cited. Among the thousands of industry, governmental, national and international standards that exist, these are by far the most prevalent. Prescriptive standards list what to do to achieve compliance and, in many cases, how to do it as well.

Goal based standards (GBS) differ from a prescriptive standards in their approach to compliance, by describing what must be achieved, rather than what must specifically be done to successfully achieve it. They do not specify the means of achieving compliance, but set tiered layers of goals that allow alternative and creative means to be compliant. While it can be argued that prescriptive standards offer a more predictable result, they also tend to restrict alternatives that may prove superior to the prescribed result. This is principally because prescriptive requirements tend to be a representation of past experience, which could become less relevant over time. As a result, they could hold back ship designers from being able to properly address future design challenges by employing evolving new technologies.

Goal-based standards are generally high-level standards and procedures, and may be described as a 'standard of standards' since these high level requirements are met through regulations, rules and standards. GBS are typically comprised of at least one goal; functional requirements associated with that goal; and verification of conformity that rules/regulations/standards meet the functional requirements and goal or goals. In order to meet the goals and functional requirements, third party certifiers, generally made up of 'recognized organizations' (ROs) and/or national agencies (typically Naval Administrations), work to choose and develop the requirements. These detailed requirements eventually become a part of the overall GBS framework. 
This is particularly advantageous when considering designs incorporating novel concepts or new innovations that have not been previously envisioned. Perhaps the most prevalent example where prescriptive standards were no longer adequate to satisfactorily address design challenges was during the revolution in shipboard control systems. As these systems transitioned from cable connected electronics networks, with modules in enclosed operating stations containing fixed circuit control cards, to programmable logic controllers (PLCs) and computer based networks, and eventually towards wireless and cloud based integration with centers external to the ship itself, classification society ${ }^{1}$ rule sets were continually challenged to keep pace. Rule requirements for these types of control systems, which were progressively melding fixed purpose electronic circuits with programmable information networks, were becoming outdated quicker than the rules were being updated. For this reason, these rules moved away from prescriptive standards towards performance and goal based rules that relied more on failure mode and effects analyses (FMEA) and verification and validation techniques $(\mathrm{V} \& \mathrm{~V})$.

To illustrate, the American Bureau of Shipping (ABS) now offers ABS CyberSafety ${ }^{\oplus}$ notations that include Integrated Software Quality Management (ISQM) services. Rather than the previous traditional focus on individual equipment and system components, this notation helps to deliver efficient, uninterrupted operation by providing a framework for coordinating and controlling the way software development, integration and maintenance are managed throughout the life of the asset. The software provider participates in a rigorous review of its software quality engineering

\footnotetext{
${ }^{1}$ Since the 1700s, the commercial shipping industry has employed the process of ship classification for ship design, construction and lifecycle maintenance, using the independent third-party services of recognized Classification Societies (also known as 'Class Societies'). Classification societies establish and apply technical standards (known as 'Rules') in relation to the design, construction and periodic survey of marine related facilities (including ships, craft and offshore structures). Classification addresses the life cycle of a ship or offshore unit from design to decommissioning; only classification societies are able to class ships and other marine structures. As independent arbiters of standards, these organizations are a major stakeholder in the international network of maritime safety.
}

process and procedures as documented; the program also includes an onsite assessment of execution of those processes by the development staff to verify integrity and compatibility with other software systems installed on board.

\section{Efforts to address safety in the global maritime and naval world using GBS practices}

\section{IMO}

The International Maritime Organization (IMO) is the United Nations specialized agency with responsibility for the safety and security of commercial shipping and the prevention of marine pollution by ships. As a specialized agency of the United Nations, IMO is the global standard-setting authority for the safety, security and environmental performance of international shipping. Its main role is to create a regulatory framework for the shipping industry that is fair and effective, universally adopted and universally implemented.

Formed by the United Nations in 1948, IMO is the first ever international body devoted exclusively to maritime matters.

Headquartered in the United Kingdom, it has 170 Member States and three Associate Members. Its governing body, the Assembly, meets once every two years. Between sessions the Council, consisting of 40 Member Governments elected by the Assembly, acts as the governing body of the IMO. IMO is a technical organization and most of its work is carried out in a number of committees and sub-committees.

The first conference organized by IMO in 1960 was addressing maritime safety. That conference adopted the International Convention on Safety of Life at Sea (SOLAS), which came into force in 1965, replacing a version adopted in 1948. The 1960 SOLAS Convention covered a wide range of measures designed to improve the safety of shipping. They included subdivision and stability; machinery and electrical installations; fire 
protection, detection and extinction; life-saving appliances; radiotelegraphy and radiotelephony; safety of navigation; carriage of grain; carriage of dangerous goods; and nuclear ships. IMO adopted a new version of SOLAS in 1974, which entered into force on 25 May 1980. This, along with a series of amendments developed since then, is still the governing version today. ${ }^{2}$

\section{IMO Moves toward GBS Practices}

In the 1990s, IMO's Maritime Safety Committee recognized that prescriptive requirements were unable to cope with the challenges posed by new ship designs, and attempted to incorporate a goal based philosophy into the technical requirements found in SOLAS. As experienced with ship electronics controls and computer based systems, safety regulations also need to be frequently updated to keep pace with lessons learned and the latest technologies.

The concept of goal based ship construction standards was introduced in IMO at the 89th Session of the Council in November 2002 through a joint proposal from the Governments of Bahamas and Greece (IMO MSC 77). In this proposal, it was recommended that IMO play a larger role in determining the standards to which new ships are built. Traditionally, these standards were developed by shipyards, classification societies and in some cases flag states. These ship construction standards need to be written in such a way as to permit innovative designs; but at the same time, the ships should be built so that, with proper maintenance and adequate allowance in the design for ease of inspection and survey, they will remain safe for their entire economic life.

Over the next 2 years the matter was considered by the Maritime Safety Committee, the Council

\footnotetext{
${ }^{2}$ In the commercial shipping industry, marine safety has long been addressed in a global context since the mid-nineteenth century through international conventions. This practice became more urgent after the sinking of the Titanic in 1912. This effort resulted in the first International Convention for the Safety of Life at Sea (SOLAS). Successive versions of SOLAS were released in 1929 and 1948. Soon after, the International Maritime Organization was formed. The IMO subsequently became the responsible body for SOLAS. The SOLAS Convention is generally regarded as the most important of all international treaties concerning the safety of merchant ships.
}

and finally the IMO Assembly. At its 23rd session in November 2003, "Goal-based new ship construction standards" was included in the strategic plan and the long-term work plan of the Organization. The MSC commenced detailed technical work on the development of GBS at its 78th session in May 2004, and a working group on GBS was established (MSC 79 and MSC 80) to address the research. In May 2005, it was agreed the basic principles of the IMO goal based standards would be:

- Broad, over-arching safety, environmental and/ or security standards that ships are required to meet during their lifecycle;

- The required level to be achieved by the requirements applied by class societies and other recognized organizations, Administrations and IMO;

- Clear, demonstrable, verifiable, implementable, long standing, and achievable, irrespective of ship design and technology; and

- Specific enough in order not to be open to differing interpretations

These basic principles were developed to be applicable to all goal based standards developed by IMO and not only to ship construction standards. For example, the latest IMO instruments using the GBS approach (besides the "Common Structural Rules for Bulk Carriers and Oil Tankers", called the 'Common Structural Rules' or CSR BC \& OT developed by IACS ${ }^{3}$ ) are the Polar Code, as well as the International Code of Safety for Ships Using Gases or Other Low-flashpoint Fuels (IGF Code).

The Maritime Safety Committee, at its eightyseventh session in May 2010, adopted a new SOLAS regulation (reg. II-1/3-10) on "Goal-based ship construction standards for bulk carriers and oil tankers"(resolution MSC.290(87)). This regulation, which entered into force on 1 January 2012, requires that all oil tankers and bulk carriers of $150 \mathrm{~m}$ in length and above, for which the building contract is placed on or after 1 July 2016, satisfy applicable structural requirements conforming to

\footnotetext{
3 International Association of Classification Societies.
} 
the functional requirements of the International Goal-based Ship Construction Standards for Bulk Carriers and Oil Tankers (GBS Standards). Under the GBS Standards, construction rules for bulk carriers and oil tankers of classification societies (which act as recognized organizations) or national Administrations, will be verified by international GBS Audit Teams established by IMO's Secretary-General. This scheme is based on the "Guidelines for the verification of conformity with goal-based ship construction standards for bulk carriers and oil tankers" (MSC.296(87)), or the GBS Verification Guidelines.

The basic principles and methodology that IMO would use to develop these GBS utilize 5 tiers:

\section{Tier I-Goal(s)}

- One or more high-level objective(s) to be met

Tier II - Functional Requirements

- Criteria to be satisfied in order to conform to the goal(s)

\section{Tier III - Verification of conformity}

- Procedures for verifying that the rules and regulations used conform to Tiers 1 and 2

Tier IV-Rules and Regulations (for ship design and construction)

- Detailed requirements applied by national Administrations and/or recognized organizations acting on their behalf to the design and construction of a ship in order to address Tiers 1 and 2

Tier V-Industry practices and standards

- Industry standards, codes of practice and safety and quality systems for shipbuilding, ship operation, maintenance, training, manning, etc., which may be incorporated or referenced in Tier 4

\section{Parallel Naval Efforts toward a GBS Safety Code}

At about the same time that IMO was working towards the publishing of goal based standards (from the late 1990's to the present), an ongoing effort within the global naval community - one that would see a nexus between the increased application of commercial practices for naval design and construction, along with the need for commonality of naval safety measures - was underway, one that would result in the development of naval safety requirements contained in the first Naval Safety Code.

Since before the Second World War, many navies have gained familiarity with the commercial process of classification through naval construction programs using commercial standards and processes. While most of these ships were of a noncombatant nature, such as for auxiliary support vessels, oilers and stores ships, some navies have moved into using this process of classification for combatant ships as well. Since 2000, several classification societies developed Rules to address a wide range of naval combatants. Among them are American Bureau of Shipping (ABS), Bureau Veritas (BV), Det Norske Veritas - Germanisher Lloyd (DNV-GL), Indian Register (IRS), Lloyd's Register (LR), Polish Register (PRS), Registro Italiano Navale (RINA) and Türk Loydu (TL). These rules have been applied to navy ships built for the navies around the world. However, while navies extensively employed classification society rules for hull, mechanical and electrical aspects of their ships, naval ship safety requirements were typically maintained through standards and guidance unique to each naval organization, and applied on a ship class by class basis. The challenge before them was to apply this same commercial model to develop common naval safety requirements that could be used across not only classes within a navy, but also applied across many fleets.

Starting in the late 1990's, while several classification societies worked independently with various navies to develop naval classification rules, a few approached NATO's (North Atlantic Treaty Organization) Naval Group 6 on Ship Design to suggest possible opportunities for collaboration. Both the societies and NATO NG6 agreed that the societies would be better served to coordinate their efforts, and by 2000 the Terms of Reference (ToR) was signed forming the Naval Ship Classification Association (NSCA), an organization dedicated to addressing naval design issues specific to class societies. As a sort of naval-oriented counterpart to the International Association of Classification Societies (IACS), NSCA's goal was to cooperate 
in areas related to the safe operation of naval ships. Today, the NSCA is composed of eight classification societies; ABS, BV, DNV-GL, HRS, LR, PRS, RINA, and TL.

One of the first tasks for NSCA was to investigate some recent accidents on navy ships, comparing them to similar experiences on commercial ships. The NSCA determined that one of the principal reasons for these accidents was that the navy ships were not subject to the requirements of the Safety of Life at Sea Convention (SOLAS), as are commercial ships, since Chapter 1, Regulation 3 to IMO SOLAS specifically exempts 'ships of war and troopships'.

Historically, it was never envisioned to apply SOLAS to naval designs or operations. It was recognized by the Societies that many of the requirements contained in IMO SOLAS were incompatible with navy ships for many reasons. For example, commercial ships typically have much smaller crews than comparably sized naval ships; this larger crew is to support the naval mission, which may include operation of combat systems, or repair of damage sustained in combat. In addition, there may be additional personnel onboard for marine contingents and air support crews. For these and other reasons, IMO added the Exception Clause noted in the previous paragraph.

To address this need, NSCA began work on a set of rules for addressing safety issues, to be named the Naval Ship Code. To better support this effort, as well as create an open forum between the NSCA and interested navies, the International Naval Safety Association (INSA) was established in 2008. In addition to the classification societies composing the NSCA, participants of INSA include several Navies. Today, the members consist of: Royal Australian, Canadian, Danish, French, Italian, Netherlands, Norwegian, Singaporean, South African, Swedish and UK (Royal) Navies. Today, the principal function of INSA is to continue to develop and maintain the Naval Ship Code, as well as track its application to designs around the world.

\section{The naval ship code}

\section{Introduction and Application}

The Naval Ship Code, or NSC, is intended to be a code addressing naval surface ship safety, which is based on IMO conventions, resolutions and other sources that are applicable for the majority of government ships. NSC is published by the North Atlantic Treaty Organization (NATO) as ANEP (Allied Naval Engineering Publication) 77, and approved by the nations in the NATO Naval Armaments Group. NSC was developed from the start as a goal based standard, considering what the ultimate safety intent of the designer is, and considering a range of alternative design approaches that will reach this safety goal. The goals should represent the top tiers of the framework, against which a ship is verified both at design and construction stages, and during ship operation.

The Code is applicable to all surface craft used for government, non-commercial service, such as navy, coast guard, border patrol, customs etc. It applies principally to conventional powered vessels (nonnuclear) using conventional fuels such as diesel (for example NATO F76 fuel) or intermediate fuel oils.

The Code requires that a Concept of Operations Statement (or ConOpS) be developed to compare the applicability of the criteria and standards chosen. It is noted that the ConOpS may change, perhaps several times, over the service life of a government ship. Accordingly, the criteria may need to be reconsidered over the life of the ship as the ConOpS evolves. Once this is determined, the Code can provide a path for a ship to be certified by a Naval Administration ${ }^{4}$, along with recognized organizations (RO) such as classification societies, to establish that a vessel is safe (within the limits of those aspects

${ }_{4}$ The 'Naval Administration' is the agency within a Government or Nation responsible for the safe operation of government ships. The Naval Administration may be assisted or supported by other government departments, or it may delegate this duty to another agency within the Government. For the purposes of the Naval Ship Code, the Naval Administration is that agency that is charged with the implementation of the Code (or the delegation of specific duties to a recognized organization) as part of the safety management systems for a ship. 
addressed by the Code) to operate in accordance with the ConOpS provided, as well as within the safety policies, and safety organization, of the government organization in which it will operate.

While the goal based nature of the Code allows the Naval Administration and ROs to consider alternatives to the typical safety requirements applied to commercial ships, it is important to emphasize two limitations:

1. The Naval Ship Code is not intended to be viewed as a complete and entire safety management system for a ship or fleet. It is, rather, a 'tool in the toolbox' of overall and safe operation for a fleet, and may fill an important role in the fleet or administration's safety policy.

2. It includes processes and potential solutions for the defined technical areas which can be applied to any naval ship, within the context of its operational requirements. While fully intended to apply to operating conditions and foreseeable damage scenarios applicable to peacetime and maritime security (as determined in the ConOpS), the Code is NOT intended to apply to combat operations, or its associated threat conditions. While an important part of a government operated ship intended for military or defense related operations, these are outside of the scope of the Code, and intended to be addressed separately by the appropriate departments within an Administration.

The Naval Ship Code need NOT be invoked in full; it is not mandatory (unless made mandatory in the context of a build specification or through a Naval Administration), and any nation is free to implement all - or part - of the Code as part of their national regulations applied to government ships. In addition, when applying the Code, consideration is needed to determine how the ship will continue to be verified to the Code for recertification during its service operation, in order to avoid unintended safety degradation due to modifications or modernization measures applied to the ship over its life.

\section{Framework of the NSC}

The Naval Ship Code includes three distinct Parts:

\section{Part 1: NSC Requirements}

Part 2: Solutions

Part 3: Justification and Guidance

See Fig. 1, Arrangement of the Naval Ship Code. The tiers are similar to the IMO GBS structure (See "IMO Moves toward GBS Practices"). The increasing width of the triangle as the Naval Ship Code descends through the tiers implies an increasing level of detail. In addition, the vertical diagonals within the triangle refer to different technical areas within the ship, as addressed within the chapters.

Each Part of the NSC contains essentially the same Chapters:
Chapter 0 - Using the Naval Ship Code
Chapter I - Naval Ship Safety Certification
Chapter II - Structure
Chapter III - Buoyancy, Stability and Controllability
Chapter IV - Engineering Systems
Chapter V - Seamanship Systems
Chapter VI - Fire Safety
Chapter VII - Escape, Evacuation and Rescue
Chapter VIII - Communications
Chapter IX - Navigation
Chapter X - Dangerous Goods

Part 1 contains the overall goals for the ship, and are found in Regulation 1 of Part 1, Chapter 1 ("Naval Ship Safety Certification"). In short, the ship is to be designed, built and maintained so that when operated within the determined ConOpS, the ship is (1) safe to operate and prevents injury of crew onboard; and (2) the ship still has essential safety functions for crew in foreseeable damage circumstances. It is important to note that, for "special ship concepts", these goals may be modified if agreed by the Naval Administration; but risks must still be kept as low as practicable. However, in addition to these stated goals, the Naval Administration may add additional goals. 
Fig. 1. Arrangement of the Naval Ship Code

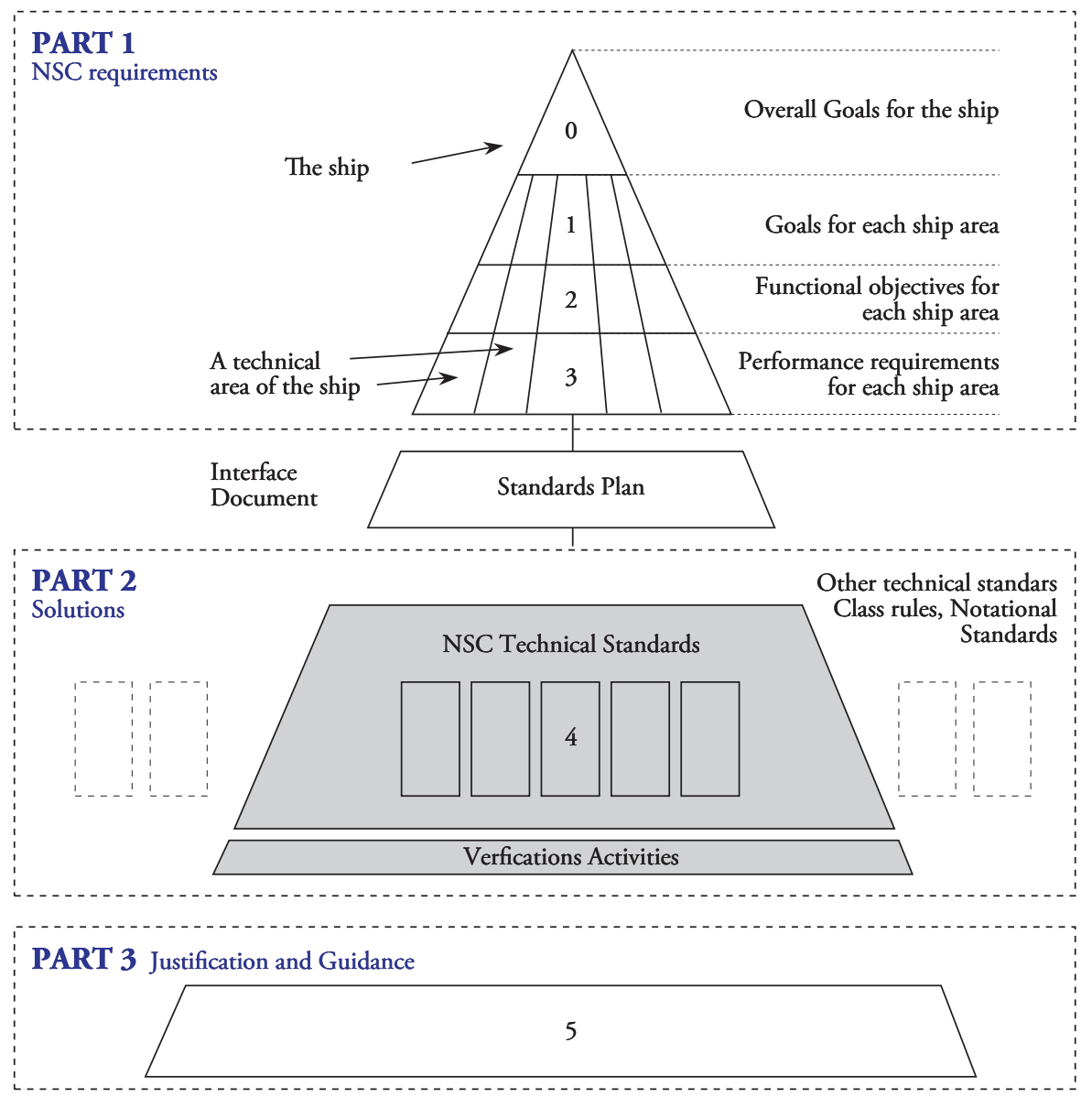

As visually demonstrated by the pyramid in Fig. 1, the top Goal is achieved through the achievement of the goals found in each chapter; these in turn are met through the successful completion of the Functional Objectives and Performance Requirements for each ship technical area. This scheme provides flexibility as to how certification may be achieved. And, while it is emphasized that the Code is not mandatory, nor must it be invoked in its entirety, use of only parts of the Code are not recommended as hazards can be interdependent on one another.

It is noted that between Part 1 and Part 2, the Figure refers to an 'interface document' described as the "Standards Plan"; this item will be discussed below in the section titled "The Process for NSC Certification".

Part 2 contains suggested solutions for the functional objectives and performance requirements in Part 1. For example, in Part 1, Chapter VII (Escape, Evacuation and Rescue), Regulation 27 addresses 'Rescue Arrangements'. The Functional Objective simply states that these arrangements shall permit persons to be rescued from the sea, whether it be from the water or some form of survival craft. The Performance Requirements add the need for these rescue arrangements to retrieve persons overboard, while minimizing risk to the crew rescuing the person. In addition, there should be a means to permit the mass rescue of persons from another vessel. This is the limit of Part 1. Meanwhile, Part 2, containing the recommended Solutions, provides far more detail. It mandates that rescue craft arrangements comply with either IMO Resolution A.656(16) "Guidelines for Fast Rescue Boats", LSA 5 Code Chapter 5 "Rescue boats", or IMO MSC/Circ.809

5 Lifesaving Appliances Code. 
"Recommendation for canopied reversible liferafts, or automatically self-righting life-rafts and fast rescue boats, including testing, on ro-ro passenger ships". It describes the number of craft to have onboard and how it is to be used; requirements applicable for the ship to be adequate to recover overboard persons; how rescue craft and lifeboats shall be launched and under what conditions; Swimmer of the Watch requirements and their equipment; Mass Rescue requirements; as well as needs for line-throwing appliance lifebuoys. As can easily be seen from this example, the solutions tend to be prescriptive as a response to the performance requirements; but even in the solutions, alternatives are presented and considered.

[Note: As shown in this example, industry, government, military or international standards (such as IMO) may be invoked as possible solutions to the performance requirements. In addition, classification society rules may be used; this exemplifies why a goal based standard is best described as a 'standard of standards' as noted earlier. This also best explains the boxes shown within Tier 2 in Fig. 1; these represent the many standards invoked to be used as solutions for Tier 1.]

Options are also provided for verification. The solutions provided (such as those listed above) may be followed; as an alternative, the rules of a classification society, international convention (such as IMO SOLAS), or a suitable alternative or additional standard may be used to facilitate verification of the performance requirements. In stating this, the Code allows the Naval Administration to continue to use the existing standards, systems and equipment used previously, should these items be verified to meet the requirements. In most cases in Part 2 , these solutions may either be verified by the Naval Administration, or by an RO (such as a classification society).

Part 3 contains the final tier of the pyramid, and provides justification and guidance to support the Naval Ship Code Performance Requirements and Solutions to adequately satisfy the Goals. In addition, and perhaps even more critical, this Part provides the history and reference data provided by all applicable parties who contributed to each part and chapter. It discusses the derivation of many of the sections, presented in tabular format. For example, referring back to our example on Rescue Arrangements, it gives the sources of the requirements (such as IMO and classification society documents and rules), as well as references provided by navy members of INSA. In this way, the guidance lays down the foundation for future development to be accomplished for the NSC.

\section{The Process for NSC Certification}

The process for certification of a government ship begins with the concept of operations statement, or $\mathrm{ConOpS}$. The ConOpS defines the ship's function, operational areas and characteristics, and serves as the basis for the certification. The ConOpS is composed of a table listing the following:

- Vessel particulars, such as:

- Mission or roles of the ship

- Dimensions

- Displacement measurements

- Speed and endurance

- Post damage capability (non-combat or threat related)

- Operational area

- Crew description

- Environmental operational limits:

- Including navigation in ice

- NSC related engineering equipment:

- Propulsion machinery/equipment

- Fire safety related systems and gear

- Communications and navigation equipment

- Maintenance and survey schemes/ periodicities

- Etc.

This is the primary input to the assessment of the ship (see Fig. 2). Once established, the ConOpS is used to begin assessing the ship to Part 1 of the NSC (from Goals to Performance Requirements). Part 2 may be applied to determine agreed upon Solutions to satisfy Tier 1. An example of a ConOpS form may be found in Part 3, Chapter I, Annex A of the NSC. 
Fig. 2. Main Regulatory Elements in the Certification Process of Ships

INPUT

ASSESSMENT OF VESSEL

OUTPUT

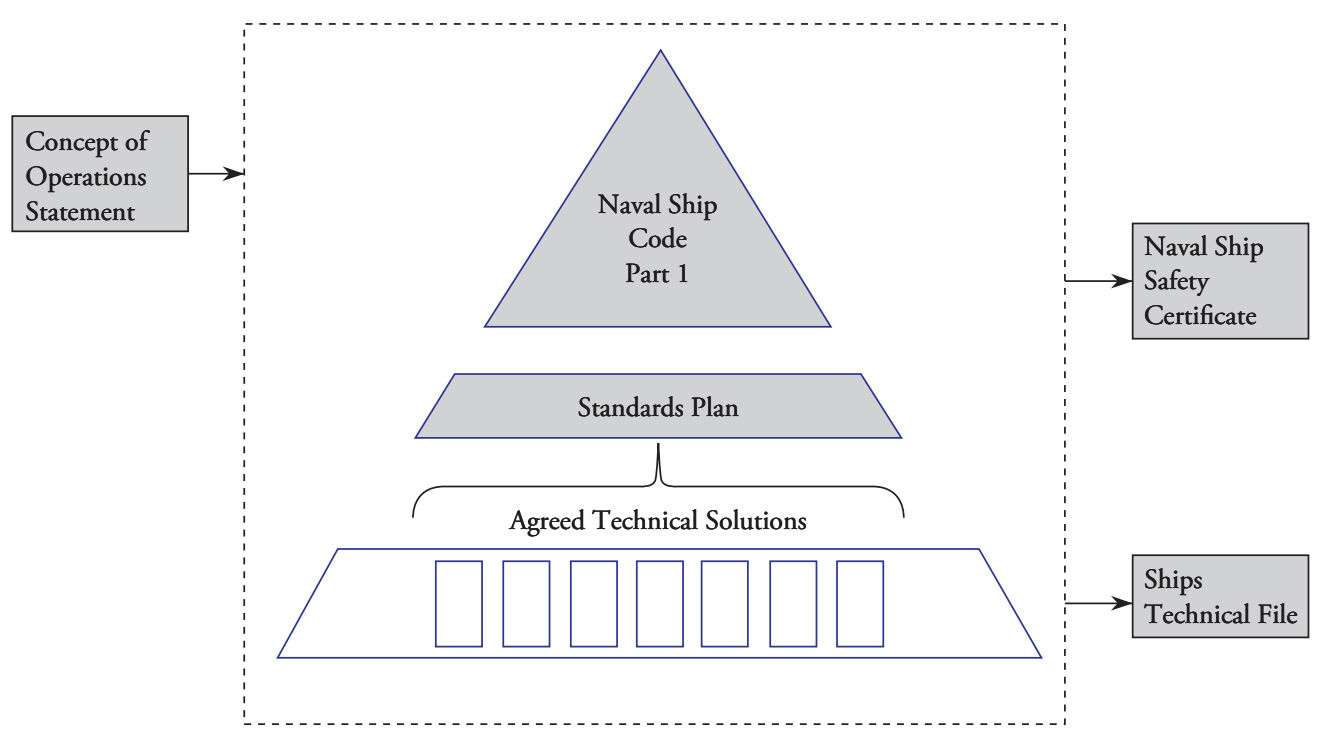

The Standards Plan is comprised of a listing of technical standards. These are used to verify that the ship meets the Goals, Functional Objectives, and Performance Requirements as verified by the Naval Administration or its recognized organization(s), within the defining parameters of the ConOpS. These may include (as examples): industry or government design standards for safety equipment; IMO conventions either applied in part or in whole; the applicable rules of a classification society; or other options for solutions deemed appropriate for use as determined by the Naval Administration. This plan (essentially a list or spreadsheet) forms the basis for the Tier 4 Solutions. An example of a Standards Plan form may be found in Part 3, Chapter I, Annex B of the NSC.

As the NSC certification process is in progress, documents are being created to maintain configuration control of the overall process. These documents will eventually be collected to create the Technical File.

A Ship's Technical File contains information as to how the requirements of the Code have been applied for the ship design and construction. The file shall be complete at delivery of a new ship, provided all aspects of the Code being invoked for this design have been addressed. A typical Technical File may include:

- A Copy of ConOpS;

- Applicable NSC Parts/Chapters being invoked

- Applicable NSC Tier level being invoked

- The complete Standards Plan

- Interpretations/Justifications made during the NSC certification process

- Classification Society information (rulesets, notations, etc.)

- Statutory certificates

- Other information as needed

The Technical File is a living document; it must be updated to address events such as modifications and modernization initiatives along the life of the ship's operation.

\section{Naval Ship Safety Certification (NSSC)}

Once the verification process is completed, the ship is issued the Naval Ship Safety Certificate (NSSC). This may be issued by the Naval Administration, or jointly with the Recognized Organization. The NSSC shall refer to information found in the ConOpS, Standards Plan, and ship construction 
files maintained by the classification society or Naval Administration. The NSSC contains the certificate itself, an Annex containing key design and verification information, and supporting data related to design information. Once completed, the NSSC then becomes part of the Technical File.

Much like a class certificate issued by a classification society, the NSSC is endorsed and renewed at regular intervals as determined by the Naval Administration.

The NSSC should be as clear as practicable in describing the technical standards used and any determinations or major assumptions made during the NSC process. An example of a NSSC form may be found in Part 3, Chapter I, Annex C of the NSC.

\section{Applying ANEP 77 to new construction and existing ships}

\section{ANEP 77 and the Acquisition Process}

Most modern government ship acquisition programs employ some form of a certification matrix. A 'Certification Matrix' is a table that addresses all aspects of the ship (using a system/ equipment level approach, such as the Ships Work Breakdown Structure or 'SWBS' format). Each row of the table presents a system or equipment description, subtopic within that item, applicable standard, type of certification required for that topic, and the certification agent (or certifier). For example:

\begin{tabular}{|c|c|}
\hline SWBS code: & 555 \\
\hline Description: & Fire Extinguishing Systems \\
\hline Subtopic: & Fire Pumps \\
\hline Standard: & $\begin{array}{l}\text { ABS INSG }{ }^{6} \text {, sections } 4-6-1 / 3.7 \\
\text { and } 4-7-3\end{array}$ \\
\hline Certification: & $\begin{array}{l}\text { Certified per ABS INSG 4-6- } \\
1 / 7.3 .1\end{array}$ \\
\hline Certifier: & ABS \\
\hline
\end{tabular}

Using a typical acquisition strategy, the NSC process would begin soon after the Capability

${ }^{6}$ ABS Guide for Building and Classing International Naval Ships (2017)
Development Document (CDD) is generated, as which point the ConOpS may be developed. Some items of the ConOpS (such as propulsion and safety equipment) may not be able to be completed until the completion of the Capability Production Document (CPD) or perhaps not even until detailed design is well in progress. In any case, the NSC certification process should be developed in parallel with the design and construction of the ship, as it is essentially a subset of the total ship certification matrix.

\section{Existing Ships}

It is preferable to conduct the process for Naval Ship Safety Certification at new construction; however, with adequate documentation and access to the ship, it may also be applied retroactively after the ship has begun operation.

For existing ships that are classed by a classification society, one way to begin the process (after development of a detailed ConOpS), is to build a draft Standards Plan that includes reference to the rules to which it was built, or currently applicable rules (as agreed between the classification society and the Naval Administration). Then, compare the rules to the applicable Performance Requirements found in the Code. Once this is done, there will be a number of 'gaps' between where the classification society's rule alone could not meet, or could only partially meet, the Performance Requirements. To these gaps are then applied more standards into the Standards Plan. At this point, the ship should have all of the requirements in the Code addressed, and a formal survey of the ship can begin.

\section{Developing a Standards Plan for Existing Ships}

Based on recent ABS experience with applying the NSC to two separate classes of existing naval vessels, some key insights are provided below that detail potential issues, their solutions, and additional guidance that may assist in practical implementation of the Code.

\section{Chapter O - Using the Naval Ship Code}

The foregoing discussion describes the purpose, 
scope, limitations, roles, arrangement, principles, required documentation and exemptions provided in the Code.

\section{Chapter I - Naval Ship Safety Certification}

A detailed and up to date $\mathrm{ConOpS}$ provided by the Naval Administration (Owner) is crucial to guiding the selection of applicable technical standards. The ConOpS should include details of how the ship will be operated and maintained throughout its service life including details of the ship attributes, survivability, operating environment etc.

\section{Chapter II - Structure}

Although the Code does not specify prescriptive structural design requirements, it broadly defines the design goal for safe operations as:

\section{Structural capacity $\geq$ Structural demand $x$ Safety Margin}

Several IACS classification societies, including ABS, have well developed and established naval ship rules that form a sound basis to verify the goals of this chapter are met.

\section{Chapter III - Buoyancy, Stability and Controllability} In general, the subdivision arrangement, watertight integrity and intact $\&$ damage stability requirements of applicable IMO regulations and classification society rules cover or exceed the ANEP 77 Tier 3 performance requirements.

\section{Chapter IV - Engineering Systems}

In general, the engineering system requirements of classification society rules cover or exceed the ANEP 77 Tier 3 performance requirements.

It is to be noted that certain requirements in this section may be additional to what Class Rules or IMO requirements specify for commercial vessels. These requirements may be evaluated based on the ConOpS and criticality of the safety function supported in discussion with the Naval Administration.Some examples of such requirements are listed below:

- An uninterrupted power system (UPS) for essential safety functions;
- Requirements for backup illumination of spaces;

- Redundancy of electrical distribution systems across main fire zones;

- Procedures for setting and overriding alarms and safety systems

- Software integrity (this is offered by Class as an optional notation, ISQM)

\section{Chapter V-Seamanship Systems}

The seamanship systems requirements such as for anchoring and mooring arrangements, embarkation and accessibility, etc., of the applicable IMO and IACS requirements cover or exceed the ANEP 77 Tier 3 performance requirements.

\section{Chapter VI - Fire Safety}

The fire safety requirements concerning structural fire integrity, containment of fire and active and passive means of firefighting are well covered by the extensive fire protection requirements of SOLAS and related IMO publications such as the FTP $^{7}$ Code, HSC $^{8}$ Code or the FSS ${ }^{9}$ Code.

Certain requirements related to casualty threshold, safe return to port and safe areas specified in ANEP 77 are more typically applicable per SOLAS to large commercial passenger vessels. The related prescriptive requirements are specified in detail within SOLAS; the applicability to the naval vessel under consideration may be decided based on the vessel ConOpS and in discussion with the Naval Administration.

\section{Chapter VII - Escape, Evacuation and Rescue}

The requirements related to escape, evacuation and rescue, etc., of SOLAS and related IMO publications such as the LSA Code, HSC code, etc., cover or exceed the ANEP 77 Tier 3 performance requirements.

A few requirements with regard to the number and position of the general alarm system and emergency lighting systems as well as the requirement to include these in the FMEA analysis may not fully fall within the scope of typical IMO and Class requirements

\footnotetext{
International Code for the Application of Fire Test Procedures.

8 International Code of Safety for High-Speed Craft.

9 International Code for Fire Safety Systems
} 
and may need to be evaluated based on the ConOpS and criticality of the safety functions supported in discussion with the Naval Administration.

\section{Chapter VIII - Communications}

Most requirements in this section are equivalent to those as specified in SOLAS with a few additional requirements sampled below:

- Internal communications systems need to be provided with a backup independent of the ship's power supply

- Capability for sea-to-air 2-way radio communications

- $\mathrm{GMDSS}^{10}$ system to be provided with facilities to inhibit transmission for Emissions Control (EMCON) and Electromagnetic Radiation Hazard (RADHAZ) purposes.

\section{Chapter IX-Navigation}

The Navigation requirements are equivalent to the applicable SOLAS and Class requirements, however, ANEP 77 requires mandatory compliance with the recommendatory IMO Resolution MSC/ Circ. 982 "Guidelines on Ergonomic Criteria for Bridge Equipment and Layout". Further, additional design and arrangement requirements are specified in ANEP 77 for the alternative and emergency conning positions.

\section{Chapter X - Dangerous Goods}

Where compliance with SOLAS or the IMDG ${ }^{11}$ code, in whole or part, is not compatible with the ConOpS, issues of stowage, personal protection and emergency procedures when dangerous goods are carried must be made using equivalent arrangements within the scope of SOLAS/IMDG (ex. ammunition); or using additional arrangement outside the scope of SOLAS IMDG (such as a navy specific ammunition standard); or through a risk assessment acceptable to the Naval Administration.

\section{Conclusions}

Goal based standards have enabled both commercial and government ships to maintain acceptable levels

\footnotetext{
10 Global Maritime Distress and Safety System.

11 International Maritime Dangerous Goods Code.
}

of safety for operators, Flag Administrations and Naval Administrations, while allowing for novel design innovation and technological advances related to ship design.

Typical goal based standards (GBS) contain tiers that provide progressively more detailed information. In essence, GBS are intended for developers of standards, not as the standard itself. Once a governing standard is created, designers apply it to their ship. By applying this goal based philosophy for naval ship safety, NATO ANEP 77 (Naval Ship Code) provides a comprehensive safety standard for combatant and noncombatant military ships for both NATO and non- NATO warships around the world.

As the Naval Ship Code has only been in existence for a few years, it is too early to determine how effective it has been in adequately addressing safety on new naval ships. However, the standard has gained enthusiastic support from the naval participants of INSA, and several have employed all or parts of the standard in the design and construction of their newer designs. In addition, some have initiated the process of applying the NSC to their existing classes as well. The NSC remains a living document, and both NSCA and INSA continue to improve the document to increase its effectiveness as a worldwide naval safety standard.

\section{References}

ABS Guide for Building and Classing International Naval Ships. (2017). Houston, TX: American Bureau of Shipping.

ASHE, G. M., \& DELPIZZO, R. D. (2013). Current Trends in Naval Ship Design. Arlington, VA: American Society of Naval Engineers. ASNE Day 2013 Proceedings.

DELPIZZO, RICHARD D. Goal Based Standards (GBS) and NATO Allied Naval Engineering Publication (ANEP) 77 (PowerPoint presentation only). SNAME Maritime Convention. 04 November, 2016. 
DELPIZZO, RICHARD D. (2015, April). The Global Commercial Model. SNAME MT Magazine.

International Association of Classification Societies. Retrieved February 26, 2017, from http://www.iacs.org.uk/

International Maritime Organization. Retrieved February 17, 2017, from http://www.imo.org/

Naval Ship Classification Association. Retrieved February 17, 2017, from http://www. marinetalk.com/articles-marine-companies/ art/Naval-Ship-Classification-AssociationDET00993750IN.html

Naval Ship Code Home Page. Retrieved February 17, 2017, from http://www.navalshipcode.org/

$\begin{array}{ccc}\text { NORTH } & \text { ATLANTIC } & \text { TREATY } \\ \text { ORGANIZATION } & \text { (NATO). } & \text { (2016). }\end{array}$

Naval Ship Code, Allied Naval Engineering Publication (ANEP) 77.

SOLAS, consolidated edition 2014: consolidated text of the International Convention for the Safety of Life at Sea, 1974, and its Protocol of 1988: articles, annexes and certificates. (2014). London: International Maritime Organization.

YUE, PENG, "An analysis of the implementation and future development of IMO goal-based standards" (2011).World Maritime University Dissertations. Paper 179.

\section{Figure Credits}

North Atlantic Treaty Organization (NATO). (2016). Naval Ship Code, Allied Naval Engineering Publication (ANEP) 77. 